九州大学学術情報リポジトリ

Kyushu University Institutional Repository

\title{
Predictive Numerical Analysis on the Mixing Characteristics in a Rotating Detonation Engine (RDE)
}

Mohammad Nurizat Rahman

High Speed Reacting Flow Laboratory, School of Mechanical Engineering, Faculty of Engineering, Universiti Teknologi Malaysia

Mazlan Abdul Wahid

High Speed Reacting Flow Laboratory, School of Mechanical Engineering, Faculty of Engineering, Universiti Teknologi Malaysia

Mohd Fairus Mohd Yasin

High Speed Reacting Flow Laboratory, School of Mechanical Engineering, Faculty of Engineering, Universiti Teknologi Malaysia

Ummikalsom Abidin

High Speed Reacting Flow Laboratory, School of Mechanical Engineering, Faculty of Engineering, Universiti Teknologi Malaysia

他

https://doi.org/10.5109/4372268

出版情報 : Evergreen. 8 (1)，pp.123-130，2021-03. Transdisciplinary Research and Education Center for Green Technologies, Kyushu University

バージョン：

権利関係 : 


\title{
Predictive Numerical Analysis on the Mixing Characteristics in a Rotating Detonation Engine (RDE)
}

\author{
Mohammad Nurizat Rahman ${ }^{1}$, Mazlan Abdul Wahid ${ }^{1},{ }^{*}$ Mohd Fairus Mohd \\ Yasin ${ }^{1,}$ Ummikalsom Abidin', Muhammad Amri Mazlan ${ }^{1}$ \\ ${ }^{1}$ High Speed Reacting Flow Laboratory, School of Mechanical Engineering, Faculty of Engineering, \\ Universiti Teknologi Malaysia, 81310 Skudai Johor, Malaysia
}

*Author to whom correspondence should be addressed: Email: mazlan@mail.fkm.utm.my

(Received November 27, 2020; Revised February 23, 2021; accepted March 23, 2021).

\begin{abstract}
Detonation potential in rotating detonation engine (RDE) depends on well-mixed fuel and oxidizer in the annulus. A numerical study was carried out to analyze hydrogen $\left(\mathrm{H}_{2}\right)$ - oxygen $\left(\mathrm{O}_{2}\right)$ mixing in RDE prior to the detonation. A validation was effectively achieved by comparing the expected detonation criteria with the reported experimental results where less than $10 \%$ error was observed. Non-reacting flow inside the annulus was examined with a new parameter describing the fuel uniformity, the amplitude of the maximum deviation from the $\mathrm{H}_{2}$ average mass fraction, $\left|S_{\max }\right|$. The numerical results are generated at variable distance between the fuel injector and the oxidizer plenum, $D$ to provide insights on the fuel uniformity and the mixing efficiency. Case A3 with $D=6$ $\mathrm{mm}$ results in the worst mixing indicated by the highest $\left|S_{\max }\right|$ of 0.0156 . This happened due to the impingement of fuel stream that separates the stream into two distinctive flows and formed two major vortices that separates the fuel streams. Case A1 with $D=2 \mathrm{~mm}$ results in the best mixing indicated by the lowest $\left|S_{\max }\right|$ of 0.0012 due to the cross flow collisions of fuel and oxidizer and large turbulent region created. The location of fuel inlet situated face to face with the $90^{\circ}$ elbow wall has been predicted to generate the most significant fuel distribution imbalance within the annulus. In conclusion, prediction towards excessive fuel inhomogeneity in the annulus as one of the major factors affecting stability of detonation wave for RDE is achieved in this study.
\end{abstract}

Keywords: Rotating detonation engine; fuel injection; non-premixed reactant; computational fluid dynamics (CFD); fuel uniformity.

\section{Introduction and background}

Deflagration combustion or subsonic combustion is the major mode of combustion adopted in many existing gas turbine combustor and propulsion system. However, the deflagration mode has restricted ability in raising the fuel efficiency and lowering the emission significantly due to its significant entropy generation ${ }^{1)}$, loss of pressure ${ }^{2)}$, and slow reaction rates ${ }^{3)}$. The combustion detonation mode, in which the burning wave propagates at supersonic speed, provides tremendous capacity for a major improvement in thermal efficiency ${ }^{4}$. It happens due to massive availability of work where the entropy produced is lower ${ }^{5)}$, and the pressure is exerted throughout the combustion area ${ }^{6}$. The ultimate goal for detonation study is to use the pressure increment phenomenon in order to draw out a potentially higher work output ${ }^{7}$, in gas turbine for power generation ${ }^{13)}$ or propulsion ${ }^{9}$.

Based on the attribute of detonation, there are two standard types of detonation applications which are rotating detonation engine $(\mathrm{RDE})^{15}$ and pulsed detonation engine $(\mathrm{PDE})^{14)}$. Since PDE experiences large pressure oscillations $^{16)}$ and limited in operating frequency ${ }^{8)}$, the detonation study has moved to RDE. RDE is one of the novel detonation concepts with simple mechanical design but have the capability to generate an impressive power density ${ }^{15)}$. RDE is a device utilizing detonation waves wherein fuel and oxidizer are inserted from injector nozzles, the RDE annulus is filled, and the well-mixed fuel and oxidizer are detonated by an ignition from the initiator tube ${ }^{17)}$. Consequently, the production of one or more detonation waves that propagate continually around the annulus can create steady thrust ${ }^{18)}$. $\mathrm{RDE}$ is a fascinating premise, and if certain RDE concerns are addressed, it might just be the wonder of firing technology in the coming years.

Researchers have recently begun to note the significance of mixing and injection processes in the RDE annulus. Selection on either premixed or non-premixed (diffusion) reactants for RDE is another subject of interest which have been discussed by many researchers. Although inserting premixed fuel and oxidizer into the 
annulus avoids many issues resulting from the mixing of reactants, it becomes more likely to flashback into the premixed plenum and injector ${ }^{7}$. As demonstrated in RDE tests, one method to avoid detonation from spreading within the plenum and injector region is to insert the fuel and oxidizer independently. Nevertheless, the decision to mix the fuel and the oxidizer within the RDE annulus contributes in a less advantageous scenario for rotating detonation propagation. For instance, under non-premixed conditions, $20 \%$ of the propagation speed deficit was detected with regard to the optimal Chapman-Jouguet (CJ) detonation in premixed environments ${ }^{20)}$. While rotating detonation waves dispersed circularly across the annulus swallowing the fresh fuel and oxidizer mixture, once they reach the annulus, the reactants also underwent intense mixing. The flow ahead of detonation front is complicated primarily because of the contact between both the injection and the rotating detonation wave propagation resulting instabilities like shifting of propagation direction $^{23)}$, waning and waxing ${ }^{3)}$ and mode switching ${ }^{17)}$. To overcome problems and to generate stable detonation wave, research on injection design for RDE has been conducted. The injection configuration must permit for a sufficient and swift mixing of the fuel and oxidizer for stable rotating detonation wave generation, while generating minimum loss of pressure along the injection space to maintain the detonation potential.

Numerical analysis is preferred in providing comprehensive analysis on different type of injection designs impact towards the mixing behavior in RDE as experimental analysis is time and cost consuming. Furthermore, it is not easy to visualize the flow behavior via experimental procedures. In early years, 2D simulations of uniform scattered injection has been performed ${ }^{19)}$. Liu et al. ${ }^{20)}$ simulated five different slotted injection designs and Schwer et al. ${ }^{21}$ investigated the pressure generated within the injector space as rotating detonation wave propagates over a series of holes. However, in all these numerical studies, the injected reactants were premixed in the first place. There are only few numbers of numerical study that actually employed non-premixed reactants for their RDE simulation. Frolov et al. ${ }^{22)}$ executed a numerical modelling of RDE with independent injector for oxidizer and fuel. Driscoll et al. ${ }^{23}$ considered the non-premixed reactants for RDE in which flow field behavior of injection process under different injector areas, fuel injection positioning and flow rate of reactants have been investigated.
A transition from an ideal to a more practical method of modelling the injection of reactants in RDE has been carried out over the last decade. Although injection scheme is one of the element to ensure a successful RDE design, but only a few studies analyze the impact of various injection schemes towards fuel uniformity within the annulus. Therefore, the present study focuses on uniformity of the fuel-oxidizer mixture in the annulus to generate a stable rotating detonation wave in RDE at variable RDE configuration.

\section{Experimental setup}

In this work, investigation on non-premixed cases are conducted. The computational regions are derived from the RDE structures used in the experimental work of Shank ${ }^{24}$. The cross-sectional and internal views of the simplistic computational region are seen in Fig. 1. From the initial computational region, some simplifications were introduced. As our primary emphasis is on the mixing of fuel-oxidizer inside the annulus of RDE, fuel and oxidizer plenums are not incorporated. As indicated in Fig. 1, to accurately evaluate the mixing performance of oxidizer and fuel within the annulus, the actual injector configuration of RDE from the aforementioned published research is taken into account. This particular injection framework will be employed for validation purposes and as the baseline case.

The gap from the fuel injection to the oxidizer plenum, $D$, is seen in Fig.1. In analyzing the fuel inlet location effect on fuel uniformity within the annulus, parameter $D$ is varied in which small $D$ value represents a fuel inlet that is close to the oxidizer plenum. Furthermore, flow behavior of reactants are also to be analyzed with the variation of $D$ values. The $D$ value for each case can be seen in Table 1.

Table 1. $D$ value.

\begin{tabular}{|l|l|}
\hline Cases & $\boldsymbol{D}(\mathbf{m m})$ \\
\hline A1 & 2 \\
\hline A2 & 4 \\
\hline A3 & 6 \\
\hline A4 & 8 \\
\hline A5 & 10 \\
\hline
\end{tabular}




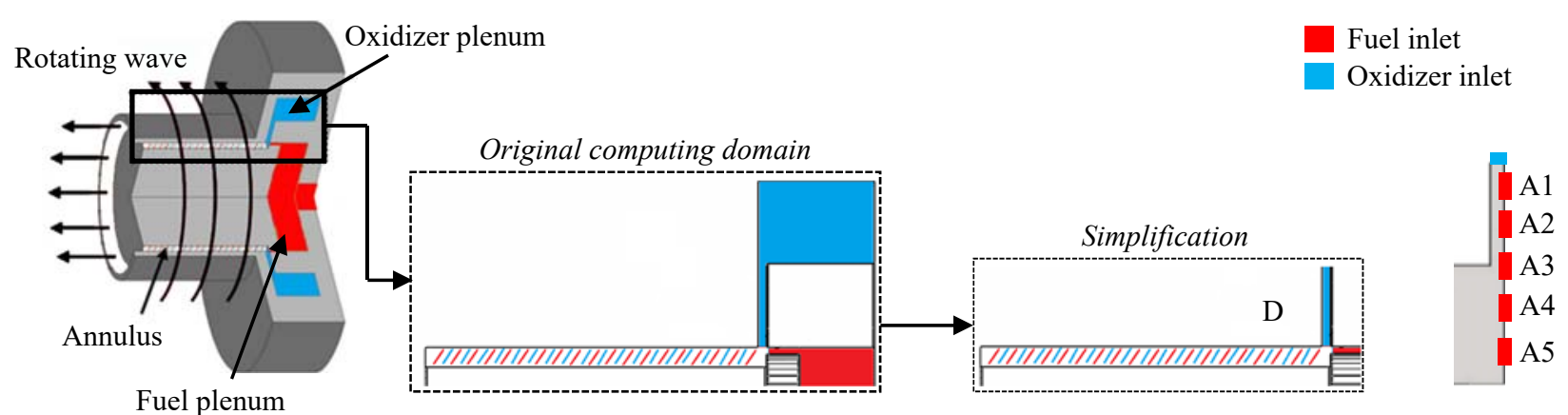

Fig. 1: Cross-sectional and internal views of the simplistic computational region.

\section{Numerical model setup}

From the finite volume technique, the computing domains were divided into smaller control volumes which covering the whole computing domain ${ }^{29}$. In ANSYS Fluent, the discretization was carried out towards the governing equations (steady state and compressible) including momentum conservation (Newton's second law), mass conservation and energy conservation (the first law of thermodynamics). Pressure-velocity coupling was solved in a coupled manner rather than segregated manner. While segregated manner for instance Semi-Implicit for Method Pressure-Linkage Equation (SIMPLE) ${ }^{27)}$ will solve the conservation of mass and conservation of momentum separately, coupled algorithm will solve both conservation of mass and momentum simultaneously thus approximations which come from segregated manner will be eliminated thus allowing dependency of mass continuity equation with momentum continuity equation, and vice versa ${ }^{25)}$. The conservation of energy equation was solved sequentially.

Using Reynolds Averaged Navier-Stokes (RANS) equations, turbulence flow was resolved as shown in eq. (1). Instantaneous Navier-Stokes equations are rewritten to RANS equations by decomposing the velocity into its instantaneous, $u$ ' and mean portions, $\bar{u}^{28)}$ and time average $^{26)}$. Implementing turbulent viscosity, $\mu_{T}$ by Boussinesq hypothesis as shown in eq. (2), Reynold stresses, $R_{\mathrm{ij}}$ in eq. (1) are formulated. In order to solve $\mu_{T}$, the SST $k-\omega$ model is used whereby transport equations are incorporated for the turbulent frequency, $\omega$ and the turbulence kinetic energy, $k^{30)}$. The SST $k-\omega$ model is employed because for this specific study, reasonably precise quality of boundary layers is essential ${ }^{25)}$ because the interaction of reactant flow with the annulus wall has an essential part for mixing efficiency because of the limited area inside the annulus.

$$
\begin{aligned}
& \rho\left(\frac{\partial \overline{u_{l}}}{\partial t}+\overline{\mu_{k}} \frac{\partial \overline{u_{l}}}{\partial x_{k}}\right)=-\frac{\partial \bar{p}}{\partial x_{i}}+\frac{\partial}{\partial x_{j}}\left(\mu \frac{\partial \overline{u_{l}}}{\partial x_{j}}\right)+\frac{\partial R_{i j}}{\partial x_{j}} \\
& R_{i j}=\mu_{T}\left(\frac{\partial \overline{u_{l}}}{\partial x_{j}}+\frac{\partial \bar{u}_{j}}{\partial x_{i}}\right)-\frac{2}{3} \mu_{T} \frac{\partial \overline{u_{k}}}{\partial x_{k}} \delta_{i j}-\frac{2}{3} \rho k \delta_{i j}
\end{aligned}
$$

Due to the unavailable non-reactive data of the fueloxidizer mixture in $\mathrm{RDE}$, the validation was performed on the basis of the previous reactive flow experiment and the reactive flow modelling was performed for validation uses. The reactive flows are obtained using the Eddydissipation model and the one-step chemical reaction of $\mathrm{H}_{2} / \mathrm{O}_{2}{ }^{3)}$. Constant flow rate under stoichiometric equivalence ratio is employed throughout the variation of $D$. This is to ensure the same mass flux of fuel and oxidizer to enter the annulus of RDE since the injection area for fuel and oxidizer are kept constant throughout the cases. The fuel mass flow rate is $5.40 \mathrm{~g} / \mathrm{s}$ and the oxidizer mass flow rate is $39.96 \mathrm{~g} / \mathrm{s}$. The reactants are pure hydrogen and oxygen. Since other variables have been fixed, the mixing efficiency study focuses solely on the effect of the fuel injector configuration.

The detailed study of the fuel uniformity within the RDE annulus was axially and radially analyzed in the current study. At regular intervals, six planes were introduced throughout the annulus. As shown in Fig. 2, each plane is subdivided into 12 circumferential areas with an angle of $30^{\circ}$ each.

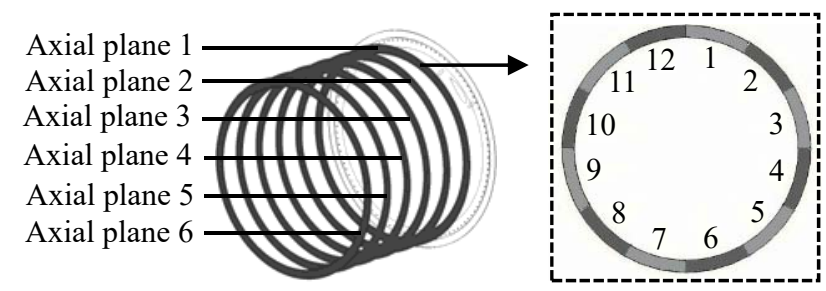

Fig. 2: Axial plane configuration in the annulus, whereby each plane is split into 12 circumferential areas.

As shown in Fig. 2, a parameter is added to measure the uniformity of fuel within the annulus, that is the amplitude of maximum deviation from the average mass fraction of $\mathrm{H}_{2},\left|S_{\max }\right| . S_{l}$ is the deviation of the $\mathrm{H}_{2}$ mass fraction from the average mass fraction of $\mathrm{H}_{2}$ for each circumferential area. The highest $S_{l}$ for each axial plane interval, $\left|S_{j}\right|$ was determined. Six values of $\left|S_{j}\right|$ are determined because there are six axial planes, and the maximum value of $\left|S_{j}\right|$ is represented as $\left|S_{\max }\right|$. 


\section{Validation (detonation modelling)}

Mesh independent was achieved at 500,000 elements with a mean element size of $2 \mathrm{~mm}$ prior to validation, together with mesh refinement to match the boundary layer on the annulus wall ${ }^{29}$. Because of the unavailable non-reactive data of the fuel-oxidizer mixture in RDE, as previously stated, the validation was carried out on the basis of the reacting flow experiment where the predicted detonation velocity, $v_{D}$ from numerical modeling was compared with the interpolated $v_{D}$ reported by Shanks experimental works ${ }^{24)} \cdot v_{D}$ is the velocity of detonation wave front travel through an explosive mixture. The interpolated $v_{D}$ comes from the interpolation of experimental data to gain the approximate $v_{D}$ at time, $t=$ $8.16 \mu \mathrm{s}$. In addition, the interpolated detonation front displacement, $r$ recorded by Shanks ${ }^{24)}$ at $t=8.16 \mu \mathrm{s}$ is compared with the results gained from the numerical study. The displacement of detonation front comes from the distance of detonation front to the initiator attached tangentially on top of RDE body which is used to detonate the mixture. The validation results are shown in Table 2.

Table 2. Comparisons between the findings of experimental and numerical work.

\begin{tabular}{|c|c|c|c|}
\hline \multirow{2}{*}{ Parameters } & \multicolumn{2}{|c|}{ Findings at $t=8.16 \mu \mathrm{s}$} & \multirow{2}{*}{$\begin{array}{l}\text { Difference } \\
\text { by } \\
\text { percentage } \\
(\%)\end{array}$} \\
\hline & Experiment & Numerical & \\
\hline$v_{D}(\mathrm{~m} / \mathrm{s})$ & 1593.8000 & 1476.4220 & 7.4 \\
\hline $\mathrm{r}(\mathrm{m})$ & 0.0156 & 0.0141 & 9.6 \\
\hline
\end{tabular}

The performance of the current CFD model is proved by these comparative analysis, as the current numerical findings are reasonably in line with the reported data. The difference by percentage between the predicted results and experimental data are $7.4 \%$ for $v_{D}$ and $9.6 \%$ for $r$. Since detonation simulation requires high computational effort, simulation was run until it reaches $t=8.16 \mu \mathrm{s}$, sufficient enough for the detonation front to emerge in the annulus. Fig. 3 shows the formation of detonation front at $t=8.16$ $\mu \mathrm{s}$.

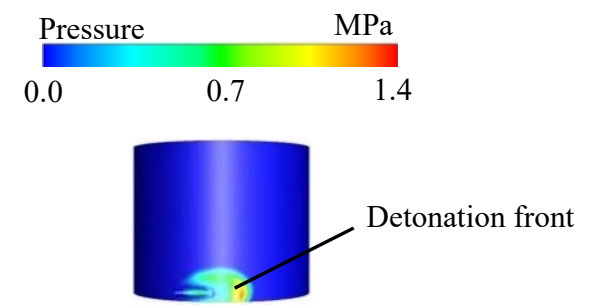

Fig. 3: The detonation front at $t=8.16 \mu$ s.

\section{Results and discussion}

In assessing the fuel uniformity axially and radially inside the RDE annulus, a collection of numerical results indicating the produced $S_{l}$ from circumferential areas are shown in Fig. 4 together with the corresponding $\left|S_{\text {max }}\right|$ of each case. Cases A3 to A5 shows significant fuel inhomogeneity as $\left|S_{\max }\right|$ values are higher in contrast to the remaining of the cases. Case A3 exhibits the highest fuel inhomogeneity where $\left|S_{\max }\right|=0.0156$. Cases A1 and A2 have been predicted to have a good uniformity of $\mathrm{H}_{2}$ within the annulus as $\left|S_{\max }\right|$ values of 0.0012 and 0.0014 are calculated for cases $\mathrm{A} 1$ and $\mathrm{A} 2$ respectively.

Graph in Fig. 5 shows the relation between $\left|S_{\text {max }}\right|$ with parameter $D$. Based on the curve generated in Fig. 5, region on the left hand side of $\mathrm{A} 3$ produced lower fuel inhomogeneity than the right hand side region. The highest $\left|S_{\max }\right|$ is generated from $\mathrm{A} 3$ in which the location of fuel injection is in the middle and facing the $90^{\circ}$ elbow wall.

To gain a better understanding towards the fuel distribution imbalance within the annulus, Fig. 6 shows a set of numerical results displaying turbulence, fuel distribution and velocity of fluid flow within the annulus. From Fig. 6 (b), the resulting fuel uniformity for cases A1 and A2 comes from the size of turbulent region when fuel inlet get closer to the oxidizer inlet. The size of turbulent region created is much larger for cases A1 and A2 as compared to other cases. Good mixing quality of the incoming reactants are important to generate lower $\left|S_{\max }\right|$ which symbolize high uniformity of fuel within the annulus. Expanding the turbulence area upstream of the annulus will boost the rate of mixing for the incoming reactants and produced homogenous mixture in the annulus as displayed in Fig. 6 (b). One similarity from A1 and $\mathrm{A} 2$ comes from the fuel impingement on the front wall before entering the annulus as shown in Fig. 6 (b). As the gap between fuel injector and front wall is really small, at $1 \mathrm{~mm}, \mathrm{H}_{2}$ and $\mathrm{O}_{2}$ collides vigorously in cross flow within this small area to enhance the turbulence and mixing.

Furthermore, as $D$ is decreasing, the incoming fuel will meet the incoming oxidizer earlier than other cases thus increased the mixing residence time prior to the introduction of mixture to the RDE annulus. Since the interaction between $\mathrm{H}_{2}$ and $\mathrm{O}_{2}$ has happened prior to the introduction of mixture to the annulus, reactants have entered the annulus as one fluid stream with an outrageous velocity that comes from the mass flow rate combination of $\mathrm{H}_{2}$ and $\mathrm{O}_{2}$, refer to Fig. 6 (c). The pressure in the center of the upstream annulus is decreased as the reactant stream experiences high velocity, thus generating flow recirculation that produces vortex flow. The vortex provides an additional boost in enhancing the mixing quality of the reactants. 


\begin{tabular}{|c|c|c|c|c|c|}
\hline $\begin{array}{l}\text { Axial } \\
\text { plane } 1\end{array}$ & $\begin{array}{r}-\infty \text { Axial } \\
\text { plane } 2\end{array}$ & $\begin{array}{l}\text { Axial } \\
\text { plane } 3\end{array}$ & $\begin{array}{r}\text { Axial } \\
\text { plane } 4\end{array}$ & $\begin{array}{l}\text { Axial } \\
\text { plane } 5\end{array}$ & $\begin{array}{r}\text { Axial } \\
\text { plane } 6\end{array}$ \\
\hline
\end{tabular}

\section{Mass fraction $\mathrm{H}_{2}$}

0.000

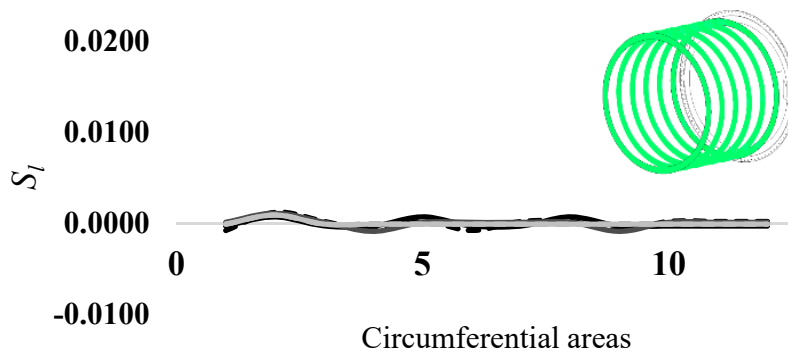

(a) $\left|S_{\max }\right|=0.0012$

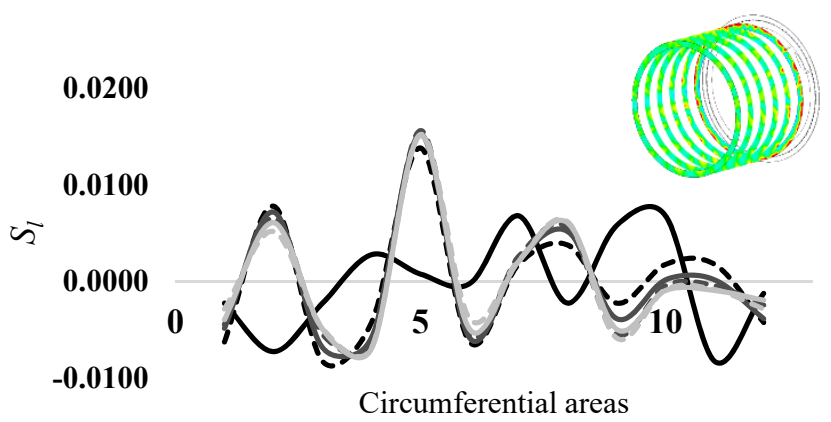

(c) $\left|S_{\max }\right|=0.0156$
0.125

$\mathbf{0 . 2 5 0}$

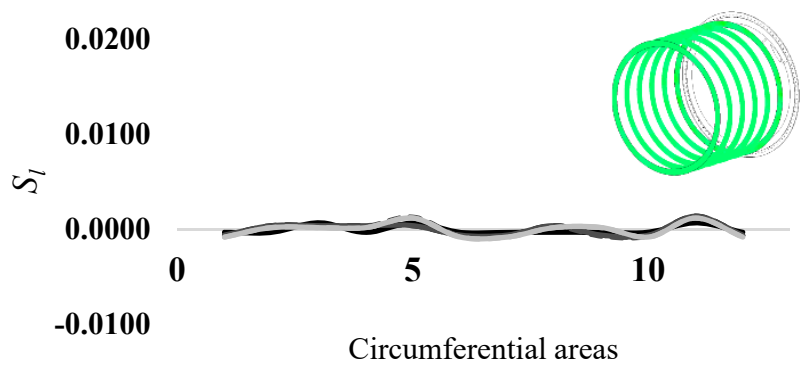

(b) $\left|S_{\max }\right|=0.0014$

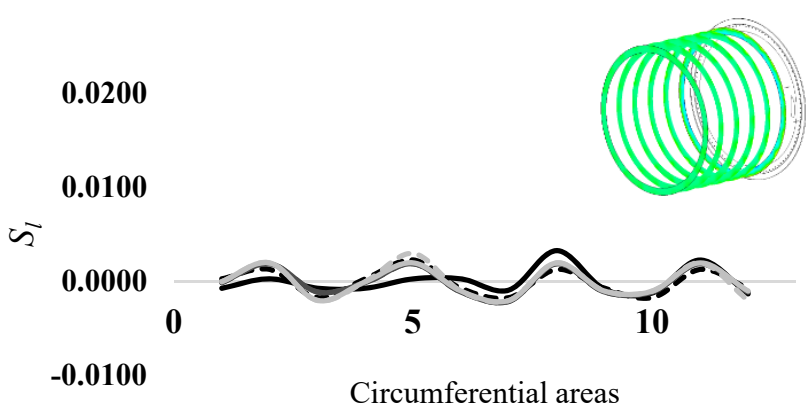

(d) $\left|S_{\max }\right|=0.0033$

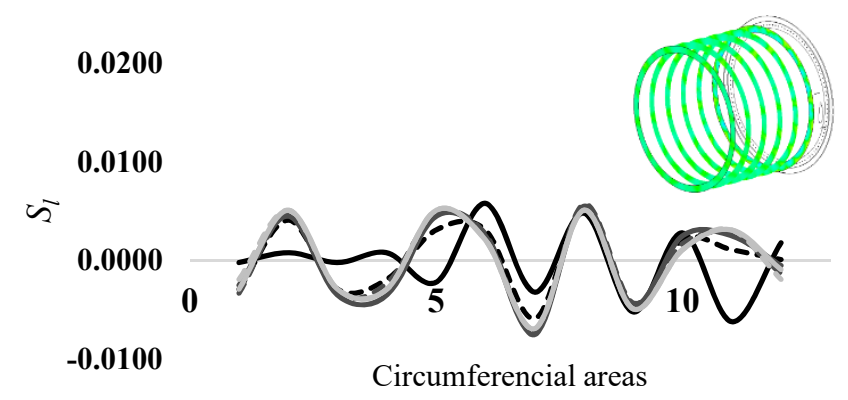

(e) $\left|S_{\max }\right|=0.0075$

Fig. 4: Graph of $S_{l}$ versus circumferential regions, contour of $\mathrm{H}_{2}$ mass fraction and $\left|S_{\text {max }}\right|$ for (a) A1, (b) A2, (c) A3, (d) A4 and (e) A5. 
Fuel inlet

Oxidizer inlet

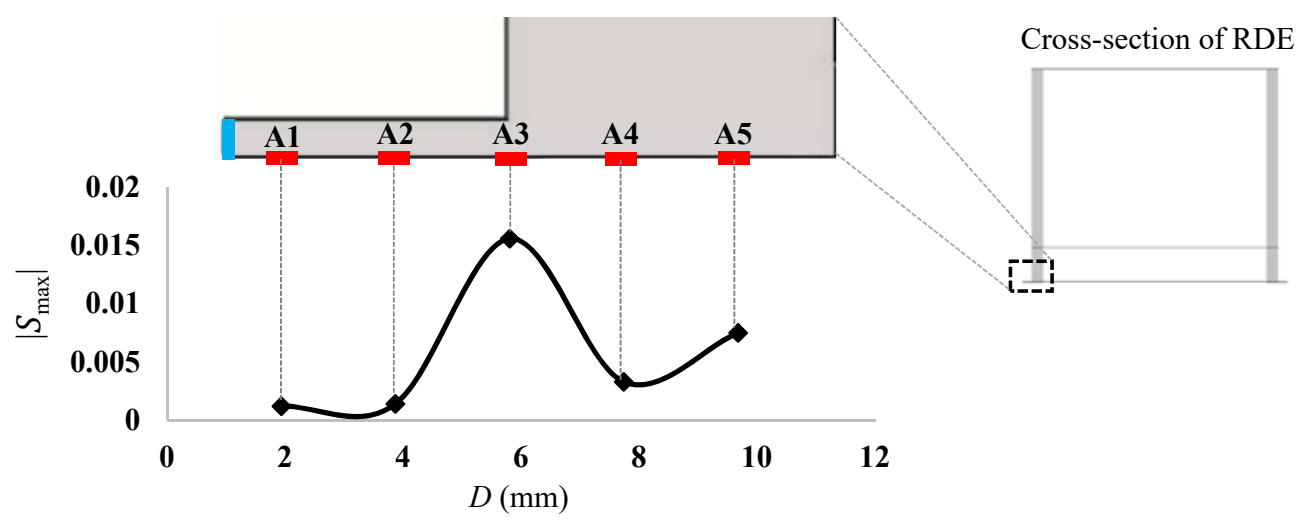

Fig. 5: Graph of $\left|S_{\max }\right|$ versus $D$.

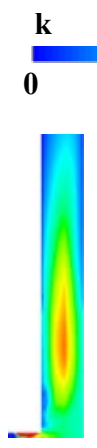

A1
500

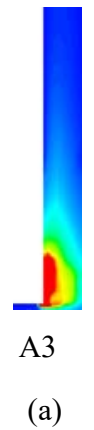

A3

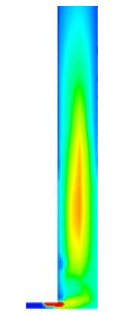

A2 (a)

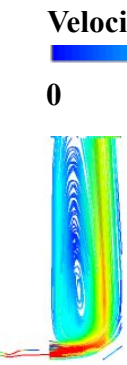

A1
Velocity

0

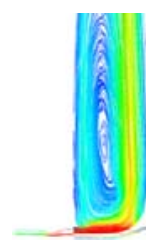

A2 $\left(\mathrm{m}^{2} / \mathrm{s}^{2}\right)$

1000

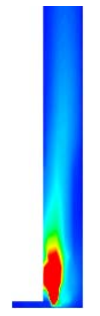

A4

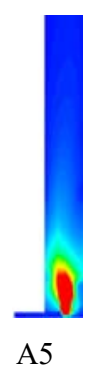

A5

(m/s)
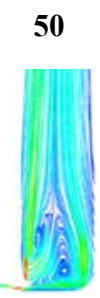

A3

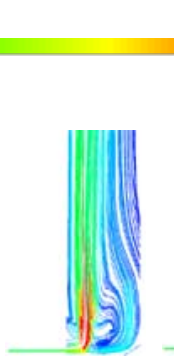

A4
100

(c)

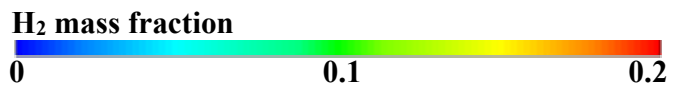

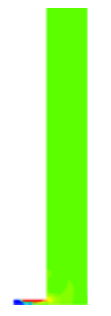

A1

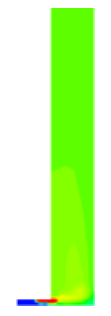

A2

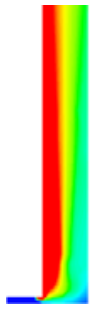

A3

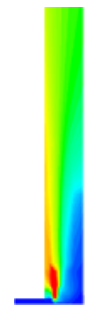

A4

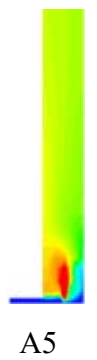

A5 (b)

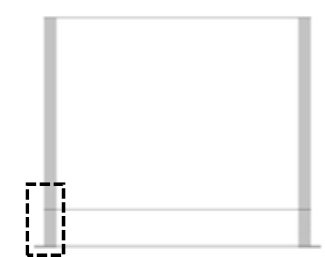

(a) and (b)

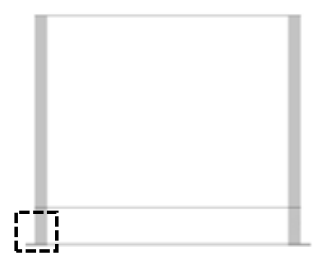

(c)

(d)

Fig. 6: The qualitative data showing (a) $k$, (b) $\mathrm{H}_{2}$ mass fraction and (c) velocity in the region upstream of annulus, dictated in (d).

From Fig. 6 (a), almost similar size of turbulent regions were created in A3, A4 and A5. Despite having insignificant difference in the size of turbulent region, information dictated in Fig. 5 shows $\left|S_{\max }\right|$ value for case $\mathrm{A} 3$ is the highest in contrast to the remaining of the cases. In the case of A3 as refer to Fig. 6 (b), high concentration of $\mathrm{H}_{2}$ was formed near the annulus outer wall, creating significant fuel inhomogeneity within the annulus. The disappearance of high velocity region in A3 as seen in Fig. 6 (c) comes from the loss of kinetic energy as some portion of fuel stream has smashed the front wall resulting some of the kinetic energy has turned into the heat energy. The depletion of kinetic energy has reduced the velocity of fuel stream in the RDE annulus. The presence of $90^{\circ}$ elbow wall has a major impact towards the reactants mixing and the disappearance of high velocity region. The impingement of fuel stream separates the incoming stream into two distinctive flows; the stream which have prior mixing with the oxidizer and another stream which has escaped to the annulus without proper mixing with the oxidizer. The stream which have prior mixing with the oxidizer smashed the annulus inner wall, creating high velocity stream close to the inner wall region while the stream that has escaped to the annulus formed 
high velocity jet close to the annulus outer wall. As the streams near the wall experiencing high velocity, the pressure in the center of the upstream annulus is decreased hence generating recirculation stream that created two vortices. These two vortices provide an additional aid in separating the fuel streams and further reduced the uniformity of fuel within the annulus.

The mixing of fuel and oxidizer in A4 and A5 are mostly occurred within the annulus as this is the region where the reactants are coming in contact. In the cases of A4 and A5 as refer to Fig. 6 (b), as the reactants going downstream, the uniformity of fuel is increased. However, fuel uniformity at upstream location is important for the stabilization of detonation wave as a poorly-mixed reactant flows will impact to formation of detonation wave since the ignitor is located at the upstream of RDE annulus.

\section{Conclusion}

In order to produce a systematized collection of numerical results following the first stage in the RDE cycle, injection and mixing of reactants prior to combustion, a detailed numerical analysis evaluating the fuel uniformity inside the RDE annulus was carried out. Validation is done by comparing $v_{D}$ and $r$ from the published experimental data. Less than $10 \%$ error was observed between the predicted and measured detonation velocity and displacement. Non-reacting flow in the annulus of RDE has been investigated in which a new parameter has been introduced to represent the fuel uniformity within the annulus called the amplitude of maximum deviation from the $\mathrm{H}_{2}$ average mass fraction, $\left|S_{\max }\right|$. The numerical results for variation of $D$ have been compared systematically to provide insights related to the generated fuel uniformity and efficiency of the mixing process. Case A 3 generates the highest $\left|S_{\max }\right|$ at 0.0156 while case A 1 generates the lowest $\left|S_{\max }\right|$ at 0.0012 . For cases $\mathrm{A} 1$ and $\mathrm{A} 2$, the distance between fuel injection and front wall is really small thus, fuel and oxidizer collides vigorously in cross flow within the small area which enhance the turbulence and mixing. For A3, the location of fuel inlet has divided the injected fuel stream and inducing recirculation in the upstream of annulus. The impingement of fuel stream in A3 separates the stream into two distinctive flows thus, high imbalance of fuel distribution is created in the upstream of annulus. The fuel uniformity is decreasing in the cases of A4 and A5, as the reactants go upstream, which would be a big issue because the ignition occurred at the upstream annulus. Therefore, it is indispensable for fuel and oxidizer to blend sufficiently in the upstream annulus. In the current study, prediction towards excessive fuel inhomogeneity in the annulus is achieved that is one of the factors influencing the detonation wave stability in RDE.

\section{Acknowledgements}

The authors would like to acknowledge their gratitude to High Impact Research (HIR) Grant UTM vote number 09G05 for the funding of the project.

\section{Nomenclature}

$\bar{p} \quad$ mean pressure (time-averaged) (pa)

$\bar{u} \quad$ mean velocity (time-averaged) $(\mathrm{m} / \mathrm{s})$

Greek symbols

$\begin{array}{ll}\delta_{i j} & \text { Kronecker delta } \\ \rho & \text { density }\left(\mathrm{kg} / \mathrm{m}^{3}\right)\end{array}$

\section{References}

1) Y. Liu, X. Sun, V. Sethi, D. Nalianda, Y. Li and L. Wang "Review of modern low emission combustion technologies for aero gas turbine engines," Progress in Aerospace Sciences., $94 \quad 12-45$ (2017). doi:10.1016/j.paerosci.2017.08.001.

2) M.A. Nemitallah, S.S. Rashwan, I.B. Mansir, A.A. Abdelhafez and M.A. Habib, "Review of Novel Combustion Techniques for Clean Power Production in Gas Turbines," Energy and Fuels., 32 (2) 979-1004 (2018). doi:10.1021/acs.energyfuels. $7 b 03607$.

3) M. Zhao and H. Zhang, "Large eddy simulation of non-reacting flow and mixing fields in a rotating detonation engine," Fuel., 280 (2020). doi:10.1016/j.fuel.2020.118534.

4) K. Wu, S. Zhang, M. Luan, and J. Wang, "Effects of flow-field structures on the stability of rotating detonation ramjet engine," Acta Astronautica., 168 174-181 (2020). doi:10.1016/j.actaastro.2019.12.022.

5) X. Liu, M. Luan, Y. Chen, and J. Wang, "Flow-field analysis and pressure gain estimation of a rotating detonation engine with banded distribution of reactants," International Journal of Hydrogen Energy., $45 \quad$ (38) 19976-19988 (2020). doi:10.1016/j.ijhydene.2020.05.102.

6) H. Zheng, Q. Meng, N. Zhao, Z. Li, and F. Deng, "Numerical investigation on $\mathrm{H}_{2}$ /Air non-premixed rotating detonation engine under different equivalence ratios," International Journal of Hydrogen Energy., 45 (3) 2289-2307 (2020). doi:10.1016/j.ijhydene.2019.11.014.

7) R. Driscoll, P. Aghasi, A.S. George, and E.J. Gutmark, "Three-dimensional, numerical investigation of reactant injection variation in a $\mathrm{H}_{2} /$ air rotating detonation engine," International Journal of Hydrogen Energy., 41(9) 5162-5175 (2016). doi:10.1016/j.ijhydene.2016.01.116.

8) Y. Zhu, G. Xu, C. Wang, L. Gong, and J. Wang, "Study on Acoustic Detection of the Working State of 
Pulse Detonation Engine," International Journal of Turbo \& Jet-Engines., 37 (1) 71-78 (2020). doi:10.1515/tjj-2018-0044.

9) S. Liu, H. Peng, W. Liu, and H. Zhang, "Effects of cavity depth on the ethylene-air Continuous Rotating Detonation," Acta Astronautica., 166 1-10 (2020). doi:10.1016/j.actaastro.2019.09.038

13) J.R. Tellefsen, "Build up and operation of an axial turbine driven by a rotary detonation engine," (2015).

14) G. Roy, S. Frolov, A. Borisov, and D. Netzer, "Pulse detonation propulsion: Challenges, current status, and future perspective," Progress in Energy and Combustion Science., 30 (6) 545-672 (2004). doi:10.1016/j.pecs.2004.05.001.

15) F.K. Lu, and E.M. Braun, "Rotating Detonation Wave Propulsion: Experimental Challenges, Modeling, and Engine Concepts," Journal of Propulsion and Power., 30 (5) 1125-1142 (2014). doi:10.2514/1.b34802.

16) J. Hoke, R. Bradley, and F. Schauer, "Impact of DDT Mechanism, Combustion Wave Speed, Temperature, and Charge," 43rd AIAA Aerospace Sciences Meeting and Exhibit., (2005). doi:10.2514/6.2005-1342.

17) W. Lin, J. Zhou, S. Liu, and F. Zhuang, "Experimental study on propagation mode of $\mathrm{H} 2$ /Air continuously rotating detonation wave," International Journal of Hydrogen Energy, 40 (4) 1980-1993 (2015). doi:10.1016/j.ijhydene.2014.11.119.

18) T. Gaillard, D. Davidenko, and F. Dupoirieux, "Numerical simulation of a Rotating Detonation with a realistic injector designed for separate supply of gaseous hydrogen and oxygen," Acta Astronautica., $141 \quad 64-78 \quad$ (2017). doi:10.1016/j.actaastro.2017.09.011.

19) S.A. Zhdan, F.A. Bykovskii and E.F. Vedernikov, "Mathematical model of a rotating detonation wave in a hydrogen-oxygen mixture," Combustion Explosion Shock Waves., 43 (4) 449-459 (2007).

20) M. Liu, R. Zhou, and J. Wang, "Numerical Investigation of Different Injection Patterns in Rotating Detonation Engines," Combustion Science and Technology,, 187 (3) 343-361 (2014). doi:10.1080/00102202.2014.923411.

21) D. Schwer, and K. Kailasanath, "Feedback into Mixture Plenums in Rotating Detonation Engines," 50th AIAA Aerospace Sciences Meeting including the New Horizons Forum and Aerospace Exposition., (2012). doi:10.2514/6.2012-617.

22) S.M. Frolov, A.V. Dubrovskii, and V.S. Ivanov "Three-dimensional numerical simulation of the operation of a rotating detonation chamber with separate supply of fuel and oxidizer," Russian Journal of Physical Chemistry B., 7 (1) 35-43 (2013). doi:10.1134/s1990793113010119.

23) R. Driscoll, A.S. George, and E.J. Gutmark, "Numerical investigation of injection within an axisymmetric rotating detonation engine," International Journal of Hydrogen Energy., $41 \quad$ (3) 2052-2063 (2016). doi:10.1016/j.ijhydene.2015.10.055.

24) C.J. Shank, "Development and testing of rotating detonation engine run hydrogen and air," (Unpublished master's thesis)., Air Force Institute of Technology, Ohio, United States of America (2012).

25) G.H. Yeoh, and K.K. Yuen "Computational Fluid Dynamics in Fire Engineering: Theory, Modelling and Practice," MA: Butterworth-Heinemann, Boston, United States of America (2009).

26) O. Takayuki, H. Taro, A. Fujio, Y. Sumio, A. Toshiyuki, Y. Koichiro and K. Yusuke, "Steady-state Analysis of Supersonic Mixing Enhanced by a Threedimensional Cavity Flow," Evergreen., 4 (1) 44-51 (2017). doi: 10.1007/s00348-014-1711-y.

27) L. Cong and I. Kazuhide, "Performance Evaluation of Wind Decontamination System by Computational Fluid Dynamics," Evergreen., 1 (2) 12-17 (2014). doi: $10.5109 / 1495158$.

28) A. M. M. Ismaiel and S. Yoshida, "Study of Turbulence Intensity Effect on the Fatigue Lifetime of Wind Turbines," Evergreen., 5 (1) 25-32 (2018). doi: 10.5109/1929727

29) A. M. Halawa, B. Elhadidi, and S. Yoshida, "Aerodynamic Performance Enhancement Using Active Flow Control on DU96-W-180 Wind Turbine Airfoil," Evergreen., 5 (1) 16-24 (2018). doi: 10.5109/1929723.

30) O. M. A. M. Ibrahim and S. Yoshida, "Experimental and Numerical Studies of a Horizontal Axis Wind Turbine Performance over a Steep 2D Hill," Evergreen., 5 (3) 12-21 (2018). doi: $10.5109 / 1957496$. 